\title{
Transformation and Cycle of Labile Substances and Production-Destruction Processes in Lake Ecosystems
}

\author{
Petr A. Lozovik and Alexandr V. Ryzhakov* \\ Northen Water Problems Institute, Karelian Research Centre RAS \\ 50 A. Nevskogo, Petrozavodsk, Karelia, 185030, Russia
}

Received 05.03.2016, received in revised form 20.01.2017, accepted 15.12.2017

To assess the rates of chemical substances transformation the kinetic equation for lake systems was applied: $\mathrm{R}=\frac{\mathrm{k} \tau}{1+\mathrm{k} \tau \mathrm{e}^{-1 / \tau}}$, where $R$ - retention capacity, $k$ - constant of transformation velocity, $\tau$-flushing period. Minimal values of transformation velocity and its constant were found for large stratified lakes. This is due to specific temperature conditions in such lakes and higher labile substances transformation because of their slow flushing period. The highest transformation rates were estimated on condition $\tau \rightarrow \infty\left(v_{\mathrm{OM}}=460, v_{\mathrm{Fe}}=7, v_{\mathrm{N}_{\mathrm{org}}}=15, v_{\mathrm{Si}}=29, v_{\mathrm{P}_{\mathrm{tot}}}=1,3 \mu \mathrm{g} / \mathrm{l}\right.$ year $)$. These values may occur in marine waters and lakes with very high $\tau$.

Average constants of rates of nitrogen cycle reactions in natural waters were estimated using kinetics of consecutive reactions of first order and field data: $\mathrm{N}_{\text {org }} \rightarrow \mathrm{NH}_{4}^{+}\left(k_{1}=0,04\right), \mathrm{NH}_{4}^{+} \rightarrow \mathrm{NO}_{2}^{-}\left(k_{2}=0,35\right)$, $\mathrm{NO}_{2}^{-} \rightarrow \mathrm{NO}_{3}^{-}\left(k_{3}=2,35\right), \mathrm{NO}_{3}^{-} \rightarrow N_{\text {org }}\left(k_{4}=1,80\right.$ day $\left.^{-1}\right)$. These constants allowed to explain typical distribution of nitrogen forms in surface waters of humid zone, where $N_{\text {org }}$ form is predominate over the rest. Phosphate turnover rate was estimated by activity of alkaline and acid phosphatases, paranitrophenilphosphate was used as substrate. The determined phosphatase activity allows estimating the time of phosphorus turnover in waters of humid zone (2 - 18 hours). Considering the high rate of phosphorus cycling (several times a day) $P_{\min }$ appears to be a very labile component and therefore its concentration in surface waters keeps low.

Production and destruction values in water bodies determined by the new kinetic model showed that production is always higher then autochthonous organic matter $(O M)$ destruction; difference between these parameters represents the quantity of a newly formed organic matter together with $\mathrm{O}_{2}$ emission into aquatic environment. The production constitutes 59-97\% of total destruction, while allochthonous OM destruction is 3-43\% of total destruction.

The water bodies trophicity could be ranged based on primary production value ( $m g \mathrm{O}_{2} / l$ year) as follows: 5-12-oligotrophic, 12-30-mesotrophic, 30-75-eutrophic, > 75 hypertrophic. Generally,

(c) Siberian Federal University. All rights reserved

* Corresponding author E-mail address: ryzhakov@nwpi.krc.karelia.ru, lozovik@nwpi.krc.karelia.ru 
trophic status of a water body determined on the basis of primary production values is similar to that estimated from $P_{\text {tot }}$.

Keywords: transformation, cycle of matter, production and destruction processes, rate constants, production, destruction, phosphatase activity, turnover of phosphorus, the water bodies of Karelia.

\title{
Трансформация, круговорот лабильных веществ и продукционно-деструкционные процессы в озерных экосистемах
}

\author{
П.А. Лозовик, А.В. Рыжаков \\ Институт водных проблем Севера \\ Карельского научного иентра РАН \\ Россия, 185030, Республика Карелия, \\ Петрозаводск, пр. А. Невского, 50
}

Для оценки трансформачии веществ использовалось кинетическое уравнение для озерных систем: $\mathrm{R}=\frac{\mathrm{k \tau}}{1+\mathrm{k} \tau \mathrm{e}^{-1 / \tau}}$, где $R-$ удерживающая способность, $k-$ константа скорости трансформации, $\tau$ - период водообмена. Наименьшие величины скоростей трансформации и их констант отмечены для больших стратифицированных озер по сравнению с малыми. Связано это как с особенностями температурных условий в водоемах, так и со степенью трансформированности лабильных веществ в озерах с замедленным водообменном. Установлены предельные значения скоростей трансформации, когда $\tau \rightarrow \infty\left(v_{\mathrm{OM}}=460\right.$ мкг/л в год, $v_{\mathrm{Fe}}=7, v_{\mathrm{N}_{\text {opг }}}=15, v_{\mathrm{Si}}=29, v_{\mathrm{P}_{\text {общ }}}=1,3$ мкг/л в год). Последние могут наблюдаться в морских водах и в озерах с очень высоким $\tau$.

С использованием кинетики последовательных реакций первого порядка и натурных данных установлены средние значения констант превращения форм азота в природных водах: $N_{\text {op }} \rightarrow \mathrm{NH}_{4}^{+}\left(k_{1}=0,04 \mathrm{cym}^{-1}\right), \mathrm{NH}_{4}^{+} \rightarrow \mathrm{NO}_{2}^{-}\left(k_{2}=0,35 \mathrm{cym}^{-1}\right), \mathrm{NO}_{2}^{-} \rightarrow \mathrm{NO}_{3}^{-}\left(k_{3}=2,35 \mathrm{cym}^{-1}\right)$, $\mathrm{NO}_{3}^{-} \rightarrow N_{\text {орг }}\left(k_{4}=1,80 \mathrm{cym}^{-1}\right)$, которые позволили объяснить преобладающее распределение форм азота в поверхностных водах гумидной зоны, где $N_{\text {ор }}$ доминирует над его минеральными формами. Оборачиваемость фосфатов оченивалась по активности щелочной и кислой фосфатаз с применением в качестве субстрата пара-нитрофенилфосфата. Путем измерения активности фосфатаз определено время оборота фосфора в водоемах гумидной зоны (2-18 ч).

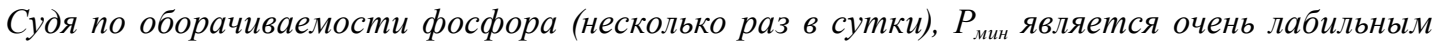
компонентом и его концентрации поддерживаются на низком уровне.

$$
-405-
$$


Определение продукционно-деструкционных характеристик водных объектов на основе их новой кинетической модели показало, что продукция всегда выше деструкции автохтонного $O B$, а их разность есть новообразование $\mathrm{OB}$ и выделение $\mathrm{O}_{2}$ в водную среду. Продукиия от общей деструкиии составляет 59-97 \%, а деструкиия аллохтонного ОВ - 3-43 \%. По величине первичной продукции (мг $\mathrm{O}_{2} / л$ в год) можно ранжировать шкалу трофности водных объектов: 5-12 - олиготрофные, 12-30-мезотрофные, 30-75 - эвтрофныле, > 75 - высокоэвтрофные. В больиинстве случаев трофический статус водоема, устанавливаемый по первичной продукиии, близок к таковой по $P_{\text {общ. }}$

Ключевые слова: трансформация, круговорот веществ, продукиионно-деструкиионные процессы, константы скорости, продукция, деструкция, фосфатазная активность, оборачиваемость фосфора, водные объекть Карелии.

\section{Введение}

В водных объектах протекают тригруппы внутриводоемных процессов: продукционнодеструкционные, трансформация лабильных веществ и круговорот биогенных элементов (БЭ), в результате которых меняются качественные показатели воды и эти процессы отражают функционирование водных экосистем. Трансформация лабильных веществ (органических (OB), P, N, Fe, Si и др.) приводит к их удалению из водной среды (захоронению в донных отложениях, биохимическому окислению до $\mathrm{CO}_{2}$ и $\mathrm{H}_{2} \mathrm{O}$ ). Круговорот БЭ способствует превращению их органических форм в минеральные, которые используются в дальнейшем живыми организмами.

Продукционно-деструкционные процессы играют важную роль в природных водах. Благодаря их протеканию обеспечиваются пищевые потребности живых организмов, происходит новообразование ОВ и выделяется кислород в водную среду. Последний процесс играет огромную роль в планетарном масштабе. Именно за счет фотосинтеза в Океане поддерживается баланс кислорода на Земле.

Для оценки степени трансформации лабильных веществ в лимнологии использует- ся понятие удерживающей способности озер: $R=\frac{C_{\text {пр }}-\mathrm{C}_{\text {оз }}}{\mathrm{C}_{\text {пр }}}(1)$, где $\mathrm{C}_{\text {пр }}, \mathrm{C}_{\text {оз }}-$ концентрация вещества в приточных водах и в озере соответственно. Для $\mathrm{P}_{\text {общ }}$ Фолленвайдером, Диллоном и Риглером получены эмпирические уравнения связи R с периодом водообмена oзep (Dillon, Rigler, 1974; Vollenweider, 1975). В предположении, что трансформация лабильных веществ подчиняется кинетике реакций первого порядка, удалось теоретически получить уравнение связи R с константой скорости трансформации и периодом водообмена озер $(\tau)$ (Лозовик и др., 2011): $R=\frac{k \tau}{1+k \tau e^{-1 / \tau}}(2)$. Польза последнего уравнения в том, что по нему, зная $\mathrm{R}$ и $\tau$, можно рассчитать $\mathrm{k}$ и установить, таким образом, важнейшие геохимические константы скорости трансформации лабильных веществ.

Круговорот азота в природных водах можно представить циклической цепью последовательных реакций первого порядка (Ryzhakov, 2013):

$\mathrm{N}_{\mathrm{opr}} \stackrel{\mathrm{k}_{1}}{\rightarrow} \mathrm{NH}_{4}+\stackrel{\mathrm{k}_{2}}{\rightarrow} \mathrm{NO}_{2}-\stackrel{\mathrm{k}_{3}}{\rightarrow} \mathrm{NO}_{3}-\stackrel{\mathrm{k}_{4}}{\rightarrow} \mathrm{N}_{\mathrm{opr}}$,

где $\mathrm{k}_{1}, \mathrm{k}_{2}, \mathrm{k}_{3}, \mathrm{k}_{4}$ - константы скоростей аммонификации, первой и второй стадий нитрификации и потребления нитратов водными 
организмами соответственно. На данной схеме показана полная нитрификация, когда $\mathrm{NH}_{4}^{+}$превращается в $\mathrm{NO}_{2}^{-}$и $\mathrm{NO}_{3}^{-}$, которая наблюдается в природных водах при хорошем насыщении воды кислородом. При дефиците $\mathrm{O}_{2}$ (в загрязненных и сточных водах) может идти неполная нитрификация - превращение $\mathrm{NH}_{4}^{+}$в $\mathrm{N}_{2} \mathrm{O}$ и в системе будет наблюдаться потеря азота (Кузнецов и др., 1985).

Круговорот фосфора в водоемах в целом сводится к взаимопревращению его минеральной $\left(\mathrm{P}_{\text {мин }}\right)$ и органической $\left(\mathrm{P}_{\text {орг }}\right)$ форм $(\mathrm{Xу-}$ пер, 1977):

$\mathrm{P}_{\text {мин }} \leftrightarrow \mathrm{P}_{\text {орг }}$

Минеральный фосфор потребляется водными организмами (бактерио- и фитопланктоном) в процессах первичной продукции и деструкции, в результате чего в водоеме аккумулируется $\mathrm{P}_{\text {орг. }}$ Обратный процесс наблюдается при деструкции органического вещества, а превращение $\mathrm{P}_{\text {орг }}$ в $\mathrm{P}_{\text {мин }}$ катализируется ферментами щелочной и кислой фосфатазами. С использованием натурных данных, лабораторного моделирования и кинетической теории последовательных реакций первого порядка Н.М. Эмануэля и Д.Г. Кнорре (1984) А.В. Рыжакову удалось получить кинетические характеристики круговорота азота в некоторых водных объектах Карелии (Ryzhakov et al., 2010; Лозовик и др., 2011; Ryzhakov, 2013), а по активности щелочной и кислой фосфатаз установить время оборота фосфора (Рыжаков, Степанова, 2016).

Для оценки продукции и деструкции OВ в водных объектах предложен новый кинетический метод, основанный на кинетике биологического потребления кислорода (БПК) и показателях содержания и трансформации автохтонного ОВ (Лозовик, 2013). Этот метод базируется на том, что результатом протекания продукционнодеструкционных процессов является образование автохтонного ОВ.

Общая деструкция ОВ вычисляется по БПК бления $\mathrm{O}_{2}(\mathrm{~K}): \quad D_{\text {общ }}=$ БПК полн $\left(1-e^{-K}\right)$ (5). Продукция (P) и деструкция автохтонного ОВ $\left(\mathrm{D}_{\text {авт }}\right)$ рассчитывается по уравнениям: $\quad P=\rho_{\mathrm{aBT}} \mathrm{XПК}\left(e^{k_{\mathrm{aBT}}}-1\right) \quad(6)$, $D_{\text {авт }}=\rho_{\text {авт }}$ ХПК $\left(1-e^{-k_{\text {авт }}}\right)(7)$, где $\rho_{\text {авт }}-$ доля автохтонного ОВ, ХПК - химическое потребление кислорода, $\mathrm{k}_{\text {авт }}$ - константа скорости окисления автохтонного ОВ.

Деструкцию аллохтонного $\mathrm{OB}$ ( $\left.\mathrm{D}_{\text {алл }}\right)$ можно определить по разности общей деструкции и деструкции автохтонного OB: $D_{\text {алл }}=D_{\text {общ }}-D_{\text {авт }}(8)$.

Новообразование ОВ и выделение $\mathrm{O}_{2}$ в водную среду в результате протекания продукционно-деструкционных процессов можно установить по разности продукции и деструкции автохтонного OB:

Новообр. $\mathrm{OB}+\mathrm{O}_{2}=\mathrm{P}-D_{\text {авт }}=$ $=\rho_{\mathrm{aBT}} \mathrm{X} К\left(e^{k_{\mathrm{aBT}}}+e^{-k_{\mathrm{aBT}}}-2\right)$.

На основании опытов по кинетике БПК удается получить БПК ного ОВ можно установить либо по эмпирической формуле $\rho_{\text {авт }}=0,62 X \Pi K / \mathrm{Hum}-0,35$ (10), где Hum - гумусность $(H u m=\sqrt{П О \cdot Ц В, ~}$ где ПО - перманганатная окисляемость воды, ЦВ - ее цветность), либо по адсорбции аллохтонного ОВ на ДЭАЭ-целлюлозе в динамическом режиме (Лозовик, Мусатова, 2013). $k_{\text {aвm }}$ можно вычислить по фиксированному значению константы трансформации аллохтонного ОВ $\left(k_{\text {алл }}\right)\left(0,0013\right.$ сут $^{-1}$ для периода открытой воды, 0,0007 сут ${ }^{-1}$ для зимнего се3она): $k_{\text {авт }}=\frac{\rho K-k_{\text {алл }}}{\rho_{\text {авт }}}+k_{\text {алл }}$ (11) или по соотношению $k_{\text {авт }}^{\rho_{\text {авт }} / k_{\text {алл }}}=10: \quad k_{\text {авт }}=\frac{\rho K}{0,9 \rho_{\text {авт }}+0,1}$ (12) (Лозовик, 2013), либо использовать их среднее значение. 
Опыты по кинетике БПК проводят при двух температурах $\left(10\right.$ и $\left.20^{\circ} \mathrm{C}\right)$, что позволяет получить температурный коэффициент скорости потребления $\mathrm{O}_{2}$ :

$$
\gamma=\frac{\left(V_{0}\right)_{20}}{\left(V_{0}\right)_{10}}
$$

Далее с использованием этого коэффициента и среднесезонной температуры воды в водном объекте можно найти продукционнодеструкционные параметры для каждого из сезонов года:

$\left(D_{\text {общ }}\right)_{t}=\left(D_{\text {общ }}\right)_{20} / \gamma^{\frac{20-t}{10}}$,

$P_{t}=(P)_{20} / \gamma^{\frac{20-t}{10}}$

$\left(D_{\text {авт }}\right)_{t}=\left(D_{\text {авт }}\right)_{20} / \gamma^{\frac{20-t}{10}}$.

Проинтегрировав сезонные значения продукционно-деструкционных характеристик, можно получить их годовые величины.

Цель данной работы заключается в обобщении и анализе результатов, полученных в лаборатории гидрохимии и гидрогеологии ИВПС КарНЦ РАН при исследованиях внутриводоемных процессов в водных объектах гумидной зоны, проведенных в период с 2010 по 2015 г. на территории Республики Карелия.

\section{Объекты и методы}

Исследование внутриводоемных процессов трансформации лабильных веществ, круговорота биогенных элементов, первичной продукции и деструкции ОВ было проведено на примере водных объектов Карелии и сопредельных областей.

Изучение трансформации лабильных веществ осуществлялось на тех объектах, для которых имелись данные по химическому балансу озер. К таким объектам относи- лись Онежское и Ладожское озера - крупные холодноводные водоемы, а также Крошнозеро, Сегозеро, Исо-Пюхяярви, Сямозеро, Вендюрское, Остер, Селецкое, Пряжинское, Водлозеро, Суоярви - малые озера, имеющие различный период водообмена. Для расчета удерживающей способности использовались средневзвешенные по объему концентрации веществ в озерных и приточных водах. Под приточными водами понимаются все воды, поступающие в озеро. Это речные воды, атмосферные осадки, подземные воды, разгружающиеся непосредственно в озеро. Кроме того, учитывался антропогенный сток с селитебных территорий, расположенных на побережье озера, а также со свалок бытовых и промышленных отходов. При наличии рыбоводческих хозяйств на озере во внимание также принималось поступление БЭ, ОВ от этих хозяйств. Для учета испарения с поверхности озера осуществлялся перерасчет концентрации веществ в притоке в озеро на объем стока из озера. В качестве $\tau$ использовалось значение, рассчитанное по стоку из озера.

Исследования круговорота форм азота были проведены на озерах Онежское, Чучьярви, Крошнозеро, Кривое, реках Лососинка, Шуя и Петрозаводской губе Онежского озера, а фосфатазная активность измерена в Петрозаводской губе, Онежском и Ладожском озерах и в реках Уя и Лососинка. Хотя число объектов было достаточно небольшим, полученные данные позволяют судить о круговороте форм $\mathrm{N}$ и $\mathrm{P}$.

Для характеристики продукционнодеструкционных процессов использовались данные исследований, проведенных в 2012 г. на озерах Уросозеро, Вендюрское, Вегарусъярви, Салонъярви, Крошнозеро, Святозеро, Валгомозеро, Яндомозеро, Урозеро, в 2013 г. на Петрозаводской губе, р. Шуе, Онежском 
озере, Кондопожской губе, озерах Сямозеро, Шотозеро, Белом море, в 2014 г. - на озерах Ладожское и Онежское (эпилимнион и гиполимнион), оз. Верхнее и, в 2015 г. - на Онежском озере (в районе Ивановских островов), в Петрозаводской губе, на Ладожском озере (в районе о. Валаам, на выходе из Сортавальских шхер).

\section{Результаты и обсуждение}

Как уже отмечалось, для оценки трансформации лабильных веществ в озерных экосистемах использовались данные по их содержанию в приточных водах, которые были получены за многолетний период наблюдений на этих объектах (Современное состояние..., 1998; Состояние водных..., 2007; Лозовик и др., 2016) (табл. 1). Для озер, подверженных антропогенному влиянию, учитывалось поступление веществ от всех источников формирования химического состава их воды. И прежде всего это касалось Онежского и Ладожского озер, для которых по некоторым компонентам антропогенное влияние имеет существенное значение. Остальные объекты мало подвержены антропогенному воздействию и в большей степени находятся в природном состоянии. В ОВ и $\mathrm{N}_{\text {орг }}$ учитывались только их аллохтонные составляющие, долю которых рассчитывали по эмпирической формуле: $\rho_{\text {алл }}=1,35-0,62 \frac{\text { ХПК }}{\sqrt{\text { нит }}}$ (Lozovik et al., 2007).

Как видно на табл. 1, исследованные водные объекты отличаются широкой изменчивостью содержания лабильного ОВ как в приточных водах, так и в самих озерах. В озерах с замедленным водообменном (Онежское, Ладожское, Сегозеро) отмечается самое низкое содержание $\mathrm{OB}, \mathrm{N}_{\text {орг }}, \mathrm{Fe}_{\text {общ }}, \mathrm{Si}, \mathrm{P}_{\text {общ }}$ по сравнению с более проточными водоемами. В приточных водах содержание всех компонентов выше, чем в озерах, за исключением высокопроточного оз. Суоярви, где они близки. Следует отметить, что в Ладожском озере в настоящее время содержание $\mathrm{P}_{\text {общ }}$ приближается к 10 мкг/л, в табл. 1 указано большее

Таблица 1. Содержание лабильных веществ в приточных и озерных водах

Table 1. The content of labile substances in inflow and lake waters

\begin{tabular}{|c|c|c|c|c|c|c|c|c|c|c|}
\hline \multirow{2}{*}{ Озеро } & $\overline{\mathrm{C}}_{\text {пр }}$ & $\mathrm{C}_{03}$ & $\overline{\mathrm{C}}_{\text {пр }}$ & $\mathrm{C}_{03}$ & $\overline{\mathrm{C}}_{\text {пр }}$ & $\mathrm{C}_{03}$ & $\overline{\mathrm{C}}_{\text {пр }}$ & $\mathrm{C}_{\mathrm{o3}}$ & $\overline{\mathrm{C}}_{\text {пр }}$ & $\mathrm{C}_{\mathrm{o3}}$ \\
\hline & \multicolumn{2}{|c|}{ ОВ, мг/л } & \multicolumn{2}{|c|}{$\mathrm{N}_{\text {орг }}, \mathrm{мг/л}$} & \multicolumn{2}{|c|}{$\mathrm{Fe}_{\text {общ, }}, \mathrm{мг/л}$} & \multicolumn{2}{|c|}{$\mathrm{P}_{\text {общ, }}$, мкг/л } & \multicolumn{2}{|c|}{$\mathrm{Si}$, мг/л } \\
\hline Онежское & 21,2 & 6,2 & 0,45 & 0,16 & 0,80 & 0,07 & 32 & 9 & 1,7 & 0,3 \\
\hline Ладожское & 28,5 & 8,6 & 0,54 & 0,17 & 0,48 & 0,12 & 48 & 18 & 2,1 & 0,5 \\
\hline Сегозеро & 20,1 & 6,4 & 0,46 & 0,14 & 0,73 & 0,09 & 19 & 6 & 1,8 & 1,2 \\
\hline Сямозеро & 25,1 & 12,0 & 0,56 & 0,31 & 0,69 & 0,22 & 31 & 16 & 2,4 & 1,0 \\
\hline Вендюрское & 17,7 & 7,2 & 0,51 & 0,29 & 0,83 & 0,15 & 27 & 19 & 2.1 & 2,2 \\
\hline Исо-Пюхяярви & 27,7 & 18,0 & 0,77 & 0,56 & 0,99 & 0,58 & 28 & 17 & 3,9 & 2,4 \\
\hline Остер & 21,4 & 12,8 & 0,52 & 0,36 & 0,62 & 0,20 & 19 & 14 & 1,7 & 1,6 \\
\hline Селецкое & 22,0 & 12,3 & 0,55 & 0,32 & 0,81 & 0,30 & 19 & 11 & 1,8 & 1,7 \\
\hline Крошнозеро & 26,0 & 15,8 & 0,79 & 0,49 & 0,88 & 0,35 & 100 & 53 & 3,0 & 1,3 \\
\hline Пряжинское & 30,2 & 15,8 & 0,39 & 0,34 & 0,71 & 0,48 & 67 & 46 & 3,4 & 0,9 \\
\hline Водлозеро & 32,0 & 20,7 & 0,53 & 0,29 & 1,27 & 0,51 & 44 & 32 & 1,1 & 0,5 \\
\hline Суоярви & 27,8 & 24,1 & 0,69 & 0,66 & 0,72 & 0,62 & 19 & 19 & 2,1 & 1,9 \\
\hline
\end{tabular}


значение. Наблюдения на притоках озера проводились в 1992-2007 гг., и для этого периода бралась концентрация $\mathrm{P}_{\text {общ }}$ в озере. Снижение его концентрации за последние годы связано с падением внешней фосфорной нагрузки на водосборе озера.

Имеющиеся данные по концентрации лабильных веществ в озерах и приточных водах позволяют вычислить удерживающую способность озер к этим элементам, а также, используя уравнение (2), рассчитать константу скорости их трансформации (табл. 2).

Как и следовало ожидать, наибольшую удерживающую способность имеют озера с замедленным водообменном, тогда как в проточных, например в Суоярви, она самая низкая. В некоторых озерах (Вендюрское, Селецкое, Остер) отмечается очень низкая величина $\mathrm{R}$ для кремния (меньше, чем в оз. Суоярви). В этих водоемах отмечаются близкие концентрации Si в самих озерах и в приточных водах (см. табл. 1). По-видимому, в них имеется неучтенный источник поступления $\mathrm{Si}$ в воду, к примеру, из песчаных донных отложений (пески в них занимают $>60$ \% площади дна).

Если рассмотреть изменчивость констант скорости трансформации, то в большинстве случаев отмечаются более низкие их значения в больших озерах с замедленным водообменном, а не в малых. Одна из причин таких отличий может быть связана с температурными условиями в водоемах. Большие озера холодноводные (среднегодовая температура около $4{ }^{\circ} \mathrm{C}$ ), а малые более теплые (среднегодовая температура около $7^{\circ} \mathrm{C}$ ).

Необходимо обратить внимание еще на одну особенность констант: близкие их значения для $\mathrm{P}_{\text {общ }}, \mathrm{OB}, \mathrm{N}_{\text {орг }}$ (для больших озер в среднем 0,16 , для малых - 0,43 год ${ }^{-1}$ ). Повидимому, для этих компонентов имеет место близкий механизм их трансформации. Для $\mathrm{Fe}$ константы более высокие, чем для указанных выше компонентов, а для $\mathrm{Si}$ они занимают промежуточное положение между $\mathrm{Fe}$ и

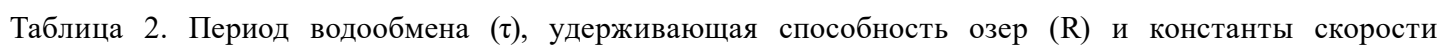
трансформации веществ (k) (Лозовик и др., 2011)

Table 2. Flushing period $(\tau)$, lake retention capacity $(\mathrm{R})$, and transformation rate constants of substances $(\mathrm{k})$ (Lozovik et al., 2011)

\begin{tabular}{|c|c|c|c|c|c|c|c|c|c|c|c|}
\hline \multirow[b]{2}{*}{ Озеро } & \multirow{2}{*}{$\begin{array}{c}\tau, \\
\text { лет }\end{array}$} & \multicolumn{2}{|c|}{$\mathrm{OB}$} & \multicolumn{2}{|c|}{$\mathrm{N}_{\mathrm{opr}}$} & \multicolumn{2}{|c|}{$\mathrm{Fe}_{\text {обш }}$} & \multicolumn{2}{|c|}{$\mathrm{P}_{\text {общ }}$} & \multicolumn{2}{|c|}{$\mathrm{Si}$} \\
\hline & & $\mathrm{R}$ & $\begin{array}{c}\mathrm{k}, \\
\text { год }{ }^{-1}\end{array}$ & $\mathrm{R}$ & $\begin{array}{c}\mathrm{k}, \\
\text { год }^{-1}\end{array}$ & $\mathrm{R}$ & $\begin{array}{c}\mathrm{k}, \\
\text { год }^{-1}\end{array}$ & $\mathrm{R}$ & $\begin{array}{c}\mathrm{k}, \\
\text { год }^{-1}\end{array}$ & $\mathrm{R}$ & $\begin{array}{c}\mathrm{k}, \\
\text { год }^{-1}\end{array}$ \\
\hline Онежское & 15,6 & 0,72 & 0,14 & 0,64 & 0,10 & 0,91 & 0,41 & 0,72 & 0,14 & 0,85 & 0,27 \\
\hline Ладожское & 11,7 & 0,70 & 0,17 & 0,69 & 0,16 & 0,75 & 0,21 & 0,63 & 0,13 & 0,74 & 0,20 \\
\hline Сегозеро & 9,95 & 0,68 & 0,18 & 0,70 & 0,19 & 0,88 & 0,43 & 0,68 & 0,18 & 0,33 & 0,05 \\
\hline Сямозеро & 3,13 & 0,52 & 0,27 & 0,45 & 0,21 & 0,68 & 0,43 & 0,48 & 0,24 & 0,58 & 0,32 \\
\hline Вендюрское & 2,29 & 0,60 & 0,42 & 0,43 & 0,26 & 0,82 & 0,76 & 0,30 & 0,16 & $-0,03$ & 0,01 \\
\hline Исо-Пюхяярви & 1,26 & 0,35 & 0,33 & 0,27 & 0,25 & 0,41 & 0,40 & 0,39 & 0,38 & 0,39 & 0,37 \\
\hline Остер & 1,16 & 0,40 & 0,42 & 0,31 & 0,31 & 0,68 & 0,82 & 0,26 & 0,38 & 0,06 & 0,06 \\
\hline Селецкое & 0,95 & 0,44 & 0,55 & 0,42 & 0,52 & 0,63 & 0,85 & 0,42 & 0,52 & 0,03 & 0,04 \\
\hline Крошнозеро & 0,88 & 0,39 & 0,51 & 0,38 & 0,49 & 0,60 & 0,85 & 0,47 & 0,63 & 0,57 & 0,80 \\
\hline Пряжинское & 0,79 & 0,48 & 0,70 & 0,13 & 0,17 & 0,32 & 0,45 & 0,31 & 0,44 & 0,74 & 1,17 \\
\hline Водлозеро & 0,50 & 0,35 & 0,74 & 0,45 & 0,97 & 0,60 & 1,30 & 0,27 & 0,57 & 0,57 & 1,23 \\
\hline Суоярви & 0,41 & 0,13 & 0,33 & 0,04 & 0,11 & 0,14 & 0,34 & 0,00 & 0,00 & 0,11 & 0,28 \\
\hline
\end{tabular}


остальными компонентами. Трансформация Fе связана в основном с гидролизом его солей и осаждением гидроксидов $\mathrm{Fe}$ (III) и $\mathrm{Fe}$ (II), $\mathrm{Si}$ - с потреблением его диатомовыми водорослями и осаждением его с отмершими клетками в донные отложения. Для $\mathrm{OB}, \mathrm{P}_{\text {общ}}, \mathrm{N}_{\text {орг }}$ имеет значение как их седиментация в составе взвешенного материала, так и их биохимическая трансформация. Имеющиеся данные по константам трансформации, концентрациям веществ в озерной воде позволяют вычислить скорости трансформации лабильных веществ как произведение концентрации на константу: $v=C \cdot k$ (табл. 3). Последнее мы вправе делать, поскольку уравнение (2) выведено исходя из предположения, что трансформация веществ в природных водах описывается кинетическим уравнением реакции первого порядка.

Как видно на табл. 3, с увеличением периода водообмена озер скорости транс- формации всех компонентов уменьшаются. Они также невысокие и в оз. Суоярви как в высокопроточном, на фоне других объектов с бо́льшим $\tau$. В этом озере вода находится незначительное время и его недостаточно для более глубокой трансформации. Такие озера, как Крошнозеро, Пряжинское и Водлозеро, отличаются очень высокой скоростью трансформации $\mathrm{P}_{\text {общ }}(18-33$ мкг/л в год). Связано это с тем, что эти озера являются эвтрофными и в них идет активное потребление фосфора на продукционные процессы, который с отмершим планктоном захоранивается в донные отложения. Полученные данные позволяют сгруппировать озера в зависимости от их водообмена в три группы:

1) большие озера с замедленным водообменном (Онежское, Ладожское, Сегозеро, $\tau_{\mathrm{cp}}=12,4$ года);

2) озера со средним водообменном (Сямозеро, Вендюрское, $\tau_{\mathrm{cp}}=2,71$ года);

Таблица 3. Скорости трансформации лабильных веществ в озерных системах

Table 3. Transformation rates of labile substances in lake systems

\begin{tabular}{|c|c|c|c|c|c|}
\hline \multirow{2}{*}{ Озеро } & OB & $\mathrm{N}_{\mathrm{opr}}$ & $\mathrm{Fe}_{\text {общ }}$ & $\mathrm{Si}$ & \multirow{2}{*}{$\begin{array}{c}\mathrm{P}_{\text {общ }} \\
\text { мкг/л в год }\end{array}$} \\
\hline & \multicolumn{4}{|c|}{ мг/л в год } & \\
\hline Онежское & 0,87 & 0,016 & 0,029 & 0,068 & 1,26 \\
\hline Ладожское & 1,46 & 0,027 & 0,025 & 0,108 & 2,34 \\
\hline Сегозеро & 1,15 & 0,027 & 0,039 & 0,060 & 1,08 \\
\hline Большие озера & 1,16 & $\mathbf{0 , 0 2 3}$ & $\mathbf{0 , 0 3 1}$ & $\mathbf{0 , 0 7 9}$ & 1,56 \\
\hline Сямозеро & 3,24 & 0,065 & 0,095 & 0,320 & 3,84 \\
\hline Вендюрское & 3,02 & 0,075 & 0,114 & - & 3,04 \\
\hline Средние озера & 3,13 & $\mathbf{0 , 0 7 0}$ & 0,105 & 0,320 & 3,44 \\
\hline Исо-Пюхяярви & 5,94 & 0,140 & 0,232 & 0,888 & 6,46 \\
\hline Остер & 5,38 & 0,112 & 0,164 & 0,096 & 5,32 \\
\hline Селецкое & 6,77 & 0,166 & 0,255 & 0,068 & 5,72 \\
\hline Крошнозеро & 8,06 & 0,240 & 0,298 & 1,040 & 33,39 \\
\hline Пряжинское & 11,06 & 0,058 & 0,216 & 1,053 & 20,24 \\
\hline Водлозеро & 15,32 & 0,281 & 0,663 & 0,603 & 18,24 \\
\hline Малые озера & 8,76 & 0,166 & 0,304 & $0,896 *$ & $5,83 * *$ \\
\hline
\end{tabular}

Примечание. * - без учета озер Остер, Селецкое, ${ }^{* *}$ - без учета эвтрофных озер Крошнозеро, Пряжинское и Водлозеро. 
3) озера с водообменном около года (ИсоПюхяярви, Остер, Селецкое, Крошнозеро, Пряжинское, Водлозеро, $\tau_{\mathrm{cp}}=0,92$ года).

Оз. Суоярви не стали включать в последнюю группу в связи с малым периодом его водообмена и поскольку по некоторым веществам получилось отсутствие их трансформации в этом озере.
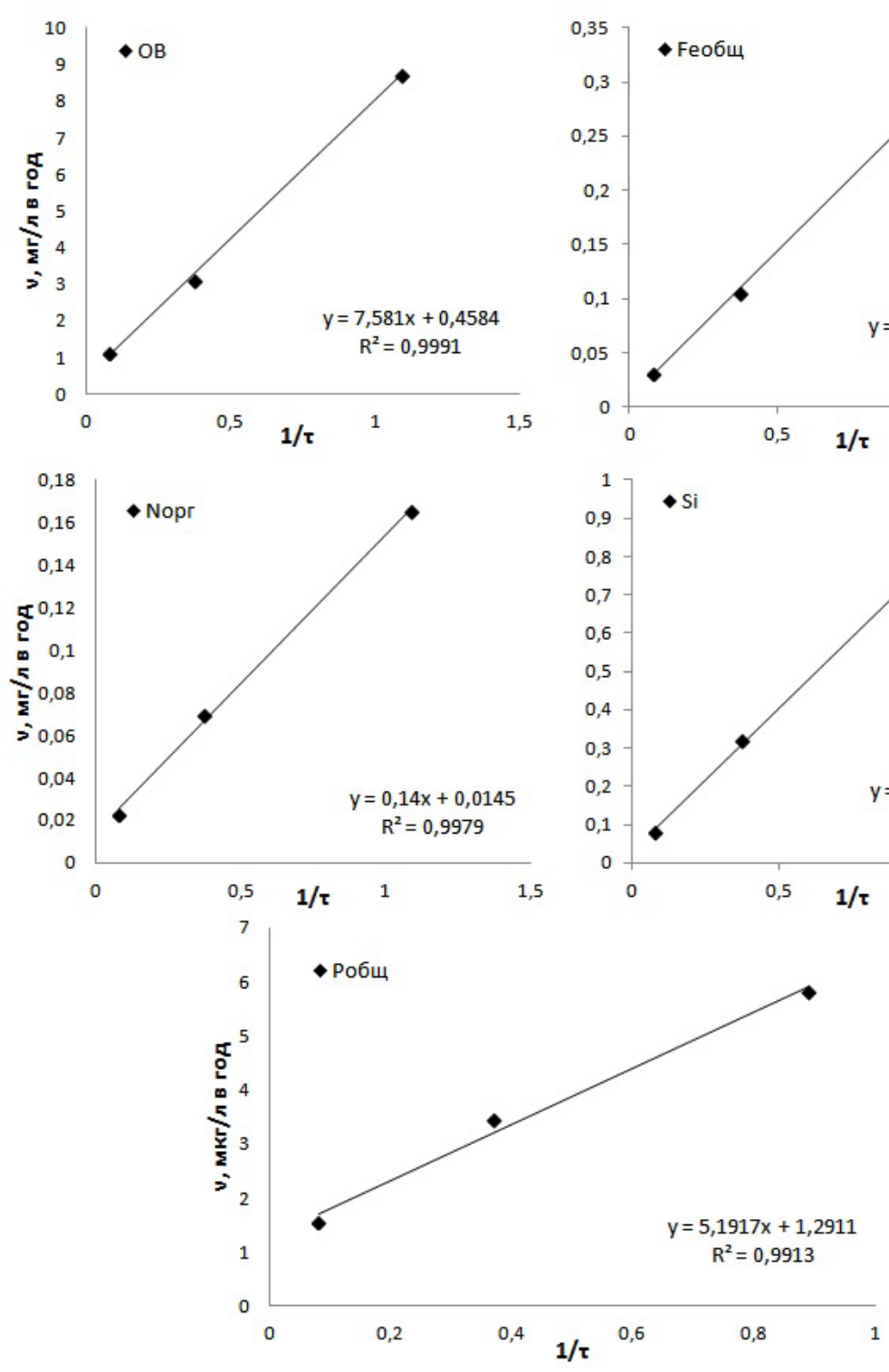

Рис. 1. Зависимости скоростей трансформации лабильных веществ от коэффициента условного водообмена $(1 / \tau)$

Fig. 1. Dependence of labile substances transformation rates on coefficient of conditional water exchange $(1 / \tau)$

$$
-412-
$$


скоростью трансформации и коэффициентом условного водообмена (коэффициент корреляции более 0,99$)$. Этот факт позволяет констатировать, что скорость трансформации лабильных веществ зависит в первую очередь от периода водообмена озер: чем он меньше, тем выше скорость. Эта закономерность будет сохраняться до значения $\tau$ около 0,5 года. Далее при снижении $\tau$ скорость будет уменьшаться в связи с недостаточностью времени для прохождения трансформации веществ. Основная причина уменьшения $v$ с ростом $\tau$ заключается в том, что чем выше $\tau$ озера, тем более трансформированы в нем вещества и тем медленнее протекает процесс их трансформации.

Полученные линейные зависимости позволяютустановитьпредельныеминимальные скорости трансформации веществ при $\tau \rightarrow \infty$. Очень высокие периоды водообмена имеют Великие Американские озера ( $\tau>100$ лет) и о3. Байкал ( $\tau-377$ лет), Мировой океан - бесконечное время. При $\tau \rightarrow \infty$ получены следующие значения скоростей трансформации (мкг/л в год): $v_{\mathrm{OB}}=460, v_{\mathrm{P}_{\text {общ }}}=1,3, v_{F e}=7$, $v_{N_{\text {орг }}}=15, v_{S i}=29$. Как видим, эти скорости за исключением ОВ очень низкие, на уровне единиц мкг и десятков мкг в литре воды в год. По-видимому, это предельные скорости и они будут наблюдаться в указанных выше объектах. В то же время следует отметить, что процесс трансформации веществ в объектах гидросферы никогда не прекращается, и он закономерное явление в природе.

Анализируя полученные данные с учетом ранее высказанного предположения о температурной зависимости трансформации веществ, необходимо отметить, что большую роль играет степень трансформированности веществ, чем температурные условия в водоемах, т.е. большее значение имеет гидрологический фактор, чем термический.
На основании натурных данных в сочетании с методами лабораторного моделирования удалось установить характеристики круговорота азотсодержащих соединений, как отдельных его стадий, так и всего цикла в целом (см. схему 3; Лозовик и др., 2011).

Так, средние значения константы аммонификации $\quad\left(N_{\text {орг }} \stackrel{k_{1}}{\rightarrow} \mathrm{NH}_{4}^{+}\right) \quad$ составляют 0,04 сут $^{-1}$, первой стадии нитрификации $\left(\mathrm{NH}_{4}^{+} \stackrel{k_{2}}{\rightarrow} \mathrm{NO}_{2}^{-}\right)-0,35$, второй стадии нитрификации $\left(\mathrm{NO}_{2}^{-} \stackrel{k_{3}}{\rightarrow} \mathrm{NO}_{3}^{-}\right)-2,35$ и ассимиляции $\mathrm{NO}_{3}^{-}\left(\mathrm{NO}_{3}^{-} \stackrel{k_{4}}{\rightarrow} N_{\text {орг }}\right)-1,80$ сут $^{-1}$. Полученные значения константы позволяют объяснить особенности распределения форм $\mathrm{N}$ в поверхностных водах гумидной зоны: $\mathrm{N}_{\text {орг }}(0,44)>>\mathrm{NH}_{4}{ }^{+}$ $(\leq 0,05) \approx \mathrm{NO}_{3}^{-}(\leq 0,05)>>\mathrm{NO}_{2}^{-}(\leq 0,001 \mathrm{мгN} /$ л $)$ (Lozovik, Borodulina, 2009). Поскольку $\mathrm{k}_{2}>>\mathrm{k}_{1}$, то в чистых природных водах не накапливается $\mathrm{NH}_{4}{ }^{+}$и он сразу превращается в $\mathrm{NO}_{2}{ }^{-}$. Опять же если $\mathrm{k}_{3}>\mathrm{k}_{2}$, то нет накопления $\mathrm{NO}_{2}^{-}$и содержание нитритов самое низкое в природных водах из всех форм N. Константы $\mathrm{k}_{4}$ и $\mathrm{k}_{3}$ одного порядка, поэтому нитраты легко потребляются водными организмами и таким образом утилизируются из водной среды. Исключение из этой закономерности составляют большие стратифицированные озера, у которых концентрация $\mathrm{NO}_{3}-$ близка или даже выше, чем $\mathrm{N}_{\text {орг }}$. Связано это с тем, что основное потребление $\mathrm{NO}_{3}^{-}$в них происходит в верхнем фотическом слое (эпилимнионе), тогда как в гиполимнионе при низких температурах и в отсутствие света нитраты - консервативный компонент экосистемы.

Проведенные исследования на некоторых водных объектах Карелии (Ладожское и Онежское озера, реки Уя, Лососинка и Петрозаводская губа) показали, что активность щелочной фосфатазы (АЩФ) составляет 0,01-0,22, а кислой (АКФ) - 0,01-0,14 мкМР/ч в литре воды, а время оборачиваемости фосфора достигает 2-18 ч (Ryzhakov, Sabylina, 
2015; Рыжаков, Степанова, 2016). Активность кислой фосфатазы немного ниже, чем щелочной, но в целом они находятся примерно на одном уровне. Однако для выбранных нами водоемов АКФ практически не влияет на интенсивность круговорота фосфора, поскольку величина $\mathrm{pH}$ в них неблагоприятна для ее функционирования. Общая фосфатазная активность определяется только АЩФ.

С учетом всех теоретических представлений, которые были отмечены во введении, проведены расчеты продукционно-деструкционных характеристик, исследованных в 2012-2015 гг. водных объектов Карелии (табл. 4, 5). Как видим, сезонная и годовая продукция всегда чуть больше, чем деструкция автохтонного ОВ (совпадение некоторых значений связано с их округлением).

Это является закономерным не только исходя из расчета по формулам (6) и (7), поскольку функция $\left(e^{k_{\text {авт }}}-1\right)$ всегда больше $\left(1-e^{-k_{\text {авт }}}\right)$, но и из логики самих процессов. Результатом их протекания должно быть новообразование ОВ и выделение кислорода в водную среду. Общая деструкция всегда выше, чем продукция. Отношение $\mathrm{P}_{\mathrm{t}} / \mathrm{D}_{\text {общ }}$ изменяется от 59 до $97 \%$. Наименьшие их значения отмечены для высокогумусных водных объектов, в которых существен вклад деструкции аллохтонного ОВ в общую деструкцию. Во всех объектах деструкция аллохтонного ОВ существенно меньше, чем автохтонного ОВ, и тем более она намного меньше, чем общая деструкция. Отношение $\mathrm{D}_{\text {алл }} / \mathrm{D}_{\text {общ }}$ изменяется в пределах 3-43\%. Наибольшие отношения (в пределах 30-40 \%) характерны для высокогумусных озер. На фоне других озер выделяются Онежское и Ладожское озера, в которых имеет место повышенное отношение $\mathrm{D}_{\text {алл }} / \mathrm{D}_{\text {общ }}$. Связано это с тем, что в этих озерах автохтонное ОВ достаточно сильно трансформировано и деструкция аллохтонного ОВ сильнее ска- зывается на общей деструкции. В высокогумусных водных объектах высокое отношение $\mathrm{D}_{\text {алл }} / \mathrm{D}_{\text {общ }}$ обусловлено большим содержанием аллохтонного $\mathrm{OB}$, хотя оно и имеет низкие скорости окисления.

Особо следует остановиться на таком новом продукционном параметре, как новообразование ОВ и выделение кислорода в водную среду в результате протекания продукционнодеструкционных процессов. Именно с использованием кинетической модели впервые удалось его определить. Самое высокое новообразование $\mathrm{OB}$ и выделение $\mathrm{O}_{2}$ в водную среду наблюдается в период открытой воды и особенно летом, когда активно идут процессы вегетации (рис. 2). Зимой их количество самое низкое, поскольку фотосинтез протекает весьма слабо.

С повышением уровня трофии водных объектов также растет новообразование ОВ и выделение $\mathrm{O}_{2}$ в водную среду. Так, в олиготрофных водоемах оно составляет 0,04$0,2 \mathrm{мгO}_{2} /$ л в год, мезотрофных - 0,1-0,3, а в эвтрофных - до $2 \mathrm{мгO}_{2} /$ л в год. Особенно велико новообразование ОВ и выделение $\mathrm{O}_{2}$ в водную среду в эвтрофных водоемах при цветении в них воды. Так, в оз. Святозеро летом 2012 г. эта величина составляла 3,3 мгО месяц, а в целом за год $-6,7 \mathrm{мгO}_{2} /$ л.

Следует отметить, что в Онежском и Ладожском озерах, а также в их заливах новообразование ОВ и выделение $\mathrm{O}_{2}$ в водную среду самое низкое на фоне других олиготрофных водоемов. В данном случае проявляются гидрологические особенности этих озер, как холодноводных с большим периодом водообмена. В то же время если учесть объем воды в этих озерах, то за год получим для Онежского озера 13000 т $\mathrm{O}_{2}$, для Ладожского - 41000 т $\mathrm{O}_{2}$. Эти значения достаточно внушительны. Поскольку мы не знаем, в какой части количество $\mathrm{O}_{2}$ соответствует новообразованию ОВ, 


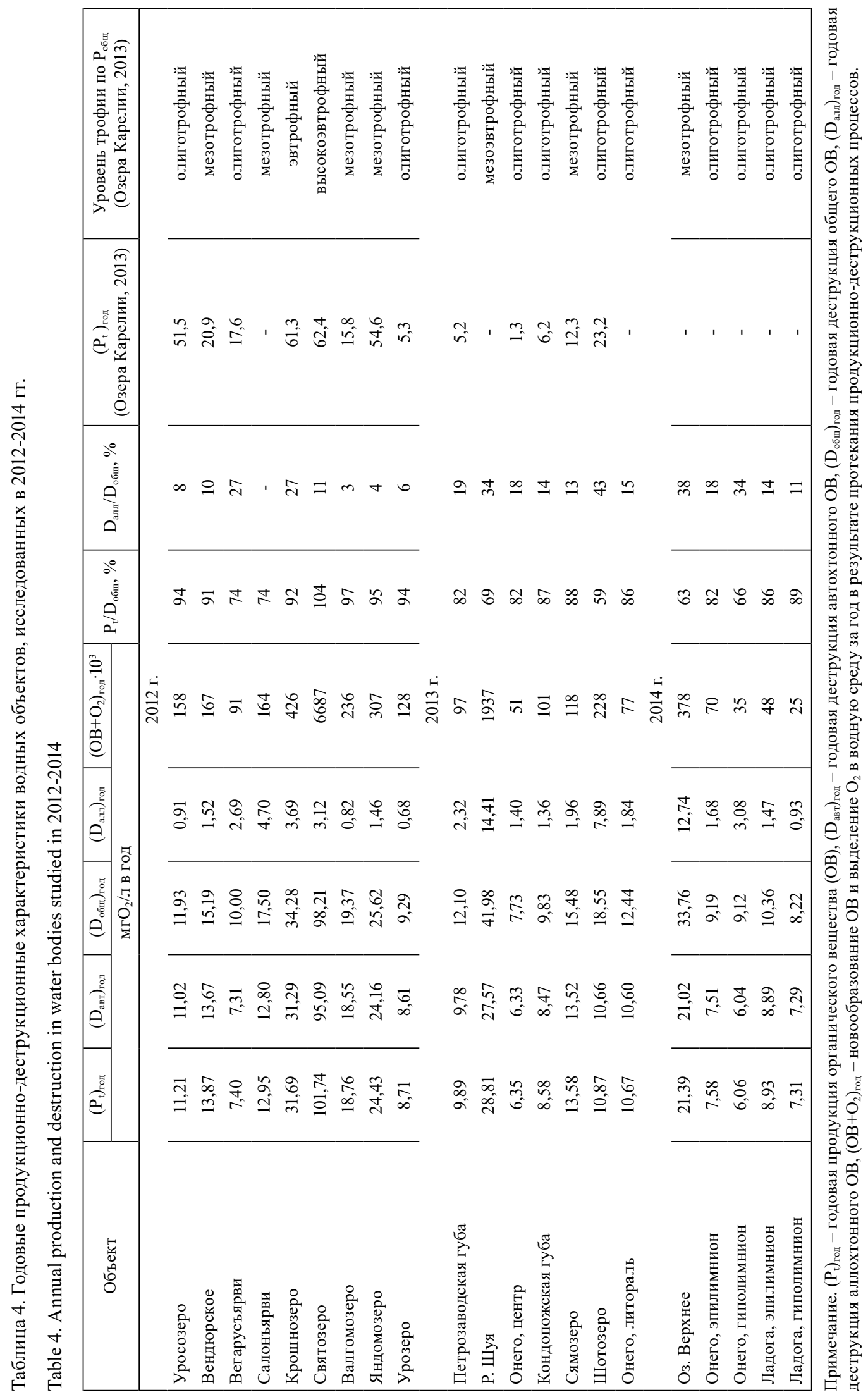




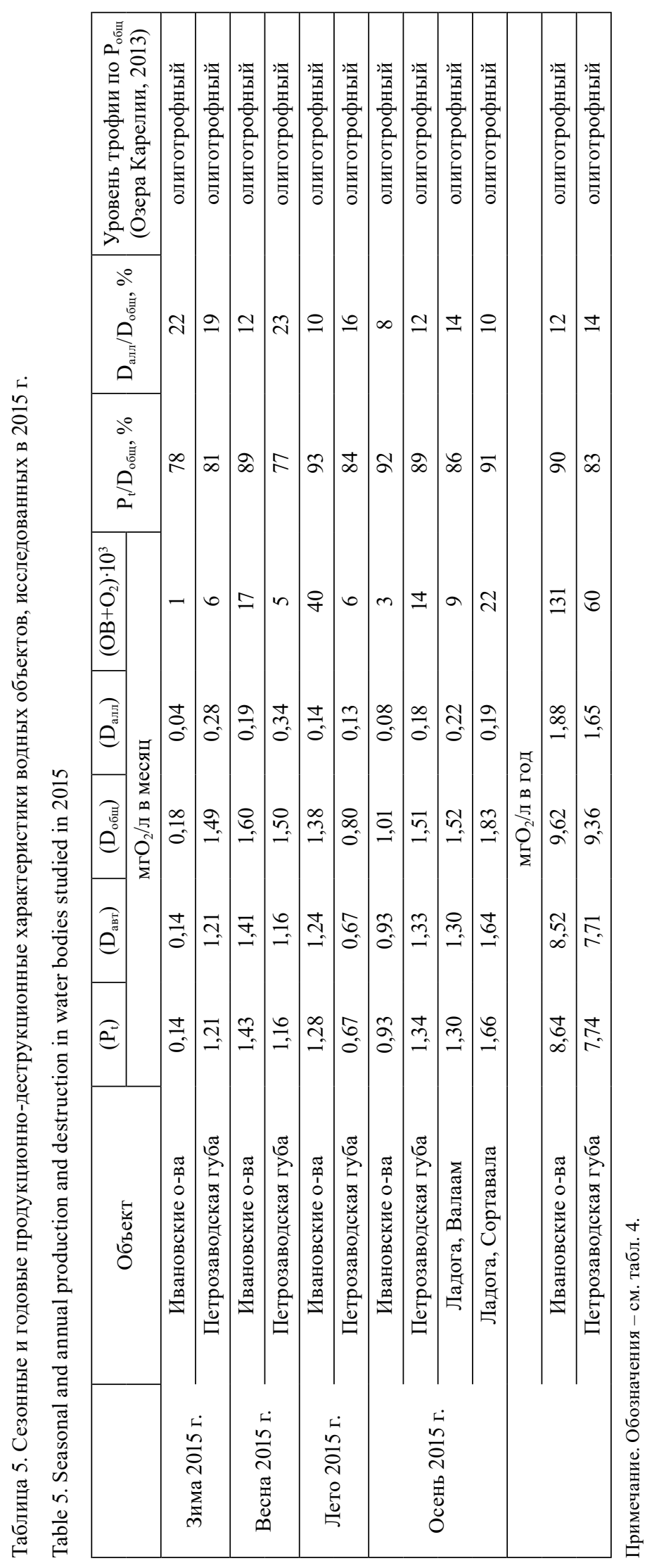




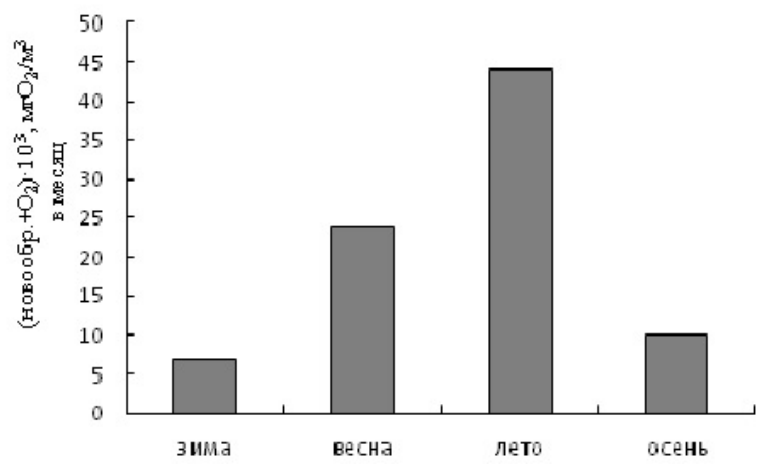

Рис. 2. Среднесезонные значения новообразования ОВ и выделения $\mathrm{O}_{2}$ в водную среду по всем исследованным объектам в 2012-2015 гг.

Fig. 2. Average seasonal values of newly formed organic matter and oxygen release into aquatic environment for all water bodies studied in 2012-2015

а в какой части - выделению $\mathrm{O}_{2}$, мы не можем точно установить по отдельности параметры для каждого процесса. Приняв их в равных долях, мы можем вычислить, какое количество $\mathrm{O}_{2}$ выделяется в водную среду в ходе продукционно-деструкционных процессов. Для поверхностных вод следует ожидать, что выделившийся $\mathrm{O}_{2}$ будет потрачен на окисление аллохтонного OB, а вот в Мировом океане, в котором отсутствует аллохтонное ОВ, это имеет огромное значение для пополнения запасов $\mathrm{O}_{2}$ на Земле. Учитывая, что средняя температура воды в больших озерах $\left(4^{\circ} \mathrm{C}\right)$ близка к средней температуре океана $\left(5^{\circ} \mathrm{C}\right)$, примем одинаковым выделение $\mathrm{O}_{2}$ в обоих объектах гидросферы (20 мгО $\mathrm{O}_{2} / \mathrm{M}^{3}$ в год). Тогда с учетом объема Мирового океана $\left(1,37 \cdot 10^{9} \mathrm{\kappa м}^{3}\right)$ ориентировочный расчет показывает, что выделение $\mathrm{O}_{2}$ в атмосферу с его поверхности может составлять $27 \cdot 10^{9}$ т/год или $0,002 \%$ от запаса $\mathrm{O}_{2}$ в атмосфере $\left(1,2 \cdot 10^{15}\right.$ т). Если сравнить полученную величину с количеством $\mathrm{O}_{2}$, которое затрачивается на сжигание ископаемого топлива, она будет весьма близкой. В литературе имеются сведения по количеству $\mathrm{CO}_{2}$, образующегося при сгорании топлива (в 2008 г. - 31,8 млрд т $\mathrm{CO}_{2}$ ), которое эквивалент- но $23,1 \cdot 10^{9}$ т $\mathrm{O}_{2}$. Эта величина соответствует рассчитанному количеству выделяемого океаном кислорода $\left(27 \cdot 10^{9} \mathrm{TO}_{2} /\right.$ год).

Загрязнение и евтрофирование отдельных участков океана приводит к повышению их продуктивности и к усилению выделения $\mathrm{O}_{2}$ в атмосферу. В конечном итоге это дает возможность поддержать баланс $\mathrm{O}_{2}$ на Земле.

В заключительной части статьи остановимся на продукционных показателях исследованных водных объектов. Наиболее высокие величины первичной продукции отмечены для озер Святозеро, Крошнозеро, р. Шуя, оз. Верхнее, которые по содержанию $\mathrm{P}_{\text {общ }}$ соответствуют эвтрофным водоемам (см. табл. 4). Высокие значения характерны для мезотрофных озер Яндомозера и Валгомозера. Для остальных объектов годовая продукция находится на уровне 6-14 мгО $/$ /л в год. Наиболее низкие величины отмечены для Ладожского и Онежского озер и их заливов (6-10 мгО 2 /л в год). В Ладожском и Онежском озерах продукция в эпилимнионе несколько выше, чем в гиполимнионе, что вполне логично, поскольку фотосинтез идет в верхних слоях воды, из которых продукты фотосинтеза попадают в нижние горизонты. 
Наблюдения на Белом море были проведены только в летний период 2013 г. При этом величина первичной продукции составляла 1,39 мг $\mathrm{O}_{2} /$ в в месяц, что близко к продукции в больших озерах.

По величине первичной продукции (мгО $\mathrm{O}_{2} /$ в год) можно ранжировать шкалу трофности водных объектов следующим образом: 5-12 - олиготрофные; 12-30 - мезотрофные; 30-75 - эвтрофные; > 75 - высокоэвтрофные. Коэффициент перехода от одного класса к другому составляет 2,5 и он совпадает с классификацией вод по трофии по со-

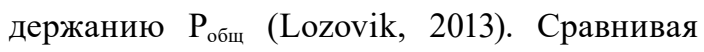
классификацию вод по трофии по величине первичной продукции с таковой по содержанию $\mathrm{P}_{\text {общ, }}$ следует отметить, что в большинстве случаев они совпадают или близки. В то же время Петрозаводская и Кондопожская губы, будучи по содержанию $\mathrm{P}_{\text {общ }}$ типично мезотрофными, по первичной продукции олиготрофные, как и сами озера, к которым они относятся. Здесь также выявлена закономерность, что заливы больших озер по величине первичной продукции больше соответствуют озерам, чем приточным водам, поступающим в них. И связано это именно с водообменом заливов с озерами, которые, собственно, и определяют особенности продуцирования ОВ в этих заливах.

Полученные величины годовой первичной продукции по кинетической модели по исследованным объектам были сопоставлены с таковыми, рассчитанными по Винбергу или Бульону, согласно данным справочника (Озера Карелии, 2013) (см. табл. 4, 5). Здесь следует отметить особенность литературных данных. Традиционно в гидробиологии принято считать продукцию на единицу площади, а не на единицу объема, как это использовалось нами. В таком случае продукция является экстенсивной величиной, т.е. зависящей от массы, и нельзя сравнивать объекты по ее величине.

Для сравнения результатов мы пересчитали продукцию с единицы площади на единицу объема, поделив первую на среднюю глубину водоема. Сравнительный анализ показал (см. табл. 4, 5), что очень редко наблюдаются близкие значения продукции по кинетической модели с таковыми, указанными в литературе. Так, по последним данным, продукция в оз. Уросозеро составляет $52 \mathrm{MгO}_{2} /$ л в год, что соответствует уровню эвтрофных водоемов, как Святозеро и Крошнозеро. Но оз. Уросозеро - это типично олиготрофный водоем. Озера Валгомозеро и Яндомозеро - близкие по многим показателям водоемы, только первое более глубокое, чем второе. Различие литературных данных по их продукции достигает более четырехкратного, а в нашем случае они близкие, только в Яндомозере, как более мелком, она выше, чем в Валгомозере.

Приводимая в литературе величина первичной продукции в Онежском озере по Винбергу весьма низкая $\left(1,3 \mathrm{MгO}_{2} /\right.$ л в год), и она в 5-6 раз меньше, чем получено по кинетической модели. Здесь необходимо отметить следующее обстоятельство. В низкопродуктивных водоемах, каким является Онежское озеро, суточное изменение концентрации $\mathrm{O}_{2}$ бывает весьма малым на уровне погрешности определения содержания $\mathrm{O}_{2}$. Поэтому в данном случае вряд ли удается надежно определить первичную продукцию.

Полученные кинетические параметры по круговороту и трансформации веществ, а также по продукционно-деструкционным процессам позволяют сравнить интенсивность их протекания в водной среде. Как видно на рис. 3, на примере Онежского озера самые низкие константы скорости характерны для трансформации лабильных веществ (вре- 


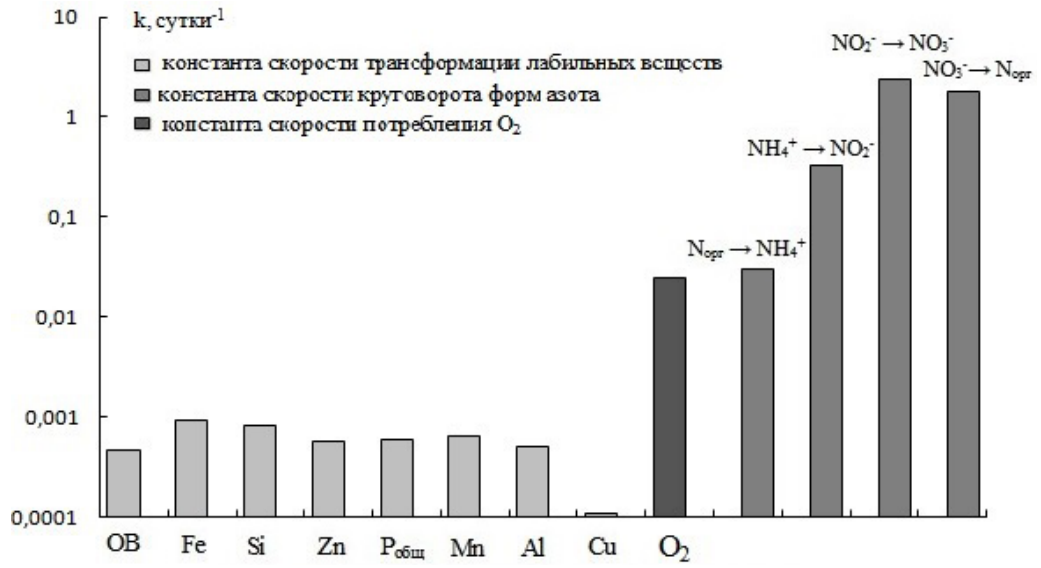

Рис. 3. Константы скоростей трансформации лабильных веществ, потребления $\mathrm{O}_{2}$ и круговорота форм азота в Онежском озере

Fig. 3. Constants of labile substances transformation rates, oxygen consumption and nitrogen cycle reactions in Onega Lake

мя их полупревращения составляет годы). Круговорот веществ протекает на порядки быстрее, а время их полупревращения - в течение суток-двух недель. Продукционнодеструкционные процессы, судя по константе скорости потребления $\mathrm{O}_{2}$, по своей интенсивности занимают промежуточное положение (время половинного потребления кислорода составляет около месяца).

В заключение отметим, что новый кинетический метод определения продукционнодеструкционных характеристик водных объектов открывает значительно большие возможности оценки функционирования водных экосистем, чем классический метод Винберга. Новый метод отличается высокой надежностью и достоверностью, достаточно прост в реализации и с успехом может быть использован на практике не только для поверхностных, но и для морских вод.

\section{Заключение}

На примере разнотипных водных объектов Карелии рассмотрены кинетические закономерности внутриводоемных процессов: продукционно-деструкционных, транс- формации лабильных веществ и круговорота биогенных элементов.

Наименьшие величины скоростей трансформации и их констант отмечены для больших стратифицированных озер по сравнению с малыми. Связано это как с особенностями температурных условий в водоемах, так и со степенью трансформированности лабильных веществ в озерах с замедленным водообменном.

С использованием кинетики последовательных реакций первого порядка и натурных данных установлены средние значения констант превращения форм азота в природных водах: $\mathrm{N}_{\text {орг }} \rightarrow \mathrm{NH}_{4}^{+}\left(\mathrm{k}_{1}=0,04\right.$ сут $\left.^{-1}\right)$, $\mathrm{NH}_{4}^{+} \rightarrow \mathrm{NO}_{2}^{-}\left(\mathrm{k}_{2}=0,35\right), \mathrm{NO}_{2}^{-} \rightarrow \mathrm{NO}_{3}^{-}\left(\mathrm{k}_{3}=2,35\right)$, $\mathrm{NO}_{3}{ }^{-} \rightarrow \mathrm{N}_{\text {орг }}\left(\mathrm{k}_{4}=1,80\right.$ сут $\left.^{-1}\right)$, которые позволили объяснить преобладающее распределение форм азота в поверхностных водах гумидной зоны, где $\mathrm{N}_{\text {орг }}$ доминирует над его минеральными формами.

Путем измерения активности фосфатаз определено время оборота фосфора в водоемах гумидной зоны (2-18 ч). Судя по оборачиваемости фосфора (несколько раз в сутки), $\mathrm{P}_{\text {мин }}$ является очень лабильным компонентом 
и его концентрации поддерживаются на низком уровне.

Определение продукционно-деструкционных характеристик водных объектов на основе их новой кинетической модели показало, что продукция всегда выше деструкции автохтонного ОВ, а их разность есть новообразование ОВ и выделение $\mathrm{O}_{2}$ в водную среду. Продукция от общей деструкции составляет
59-97\%, а деструкция аллохтонного ОВ 3-43 \%. По величине первичной продукции (мгО $\mathrm{O}_{2} / л$ в год) можно ранжировать шкалу трофности водных объектов: 5-12 - олиготрофные, 12-30 - мезотрофные, 30-75 - эвтрофные, > 75 - высокоэвтрофные.

В большинстве случаев классификация вод по трофности, устанавливаемая по первичной продукции, близка к таковой по $\mathrm{P}_{\text {общ }}$

\section{Список литературы}

Кузнецов С.И., Саралов А.И., Назина Т.Н. (1985) Микробиологические процессы круговорота углерода и азота в озерах. М., Наука, 213 с. [Kuznetsov S.I., Saralov A.I., Nazina T.N. (1985) Microbiological processes of the carbon and nitrogen cycle in lakes. Moscow, Nauka, $213 \mathrm{p}$. (in Russian)]

Лозовик П.А. (2013) Продукция и деструкция органического вещества в водных объектах по кинетической модели его трансформации в природных водах. Материалы Всероссийской научной конференции «Водная стихия: опасности, возможности прогнозирования, управления и предотвращения угроз». Новочеркасск, с. 348-355 [Lozovik P.A. (2013) Production and destruction of organic substances in water objects for a kinetic model of transformations in natural waters. Materials of all-Russian scientific conference "Water: dangers, opportunities for prediction, control and preventing threats". Novocherkassk, p. 348-355 (in Russian)]

Лозовик П.А., Бородулина Г.С., Карпечко Ю.В., Кондратьев С.А., Литвиненко А.В., Литвинова И.А. (2016) Биогенная нагрузка на Онежское озеро по данным натурных наблюдений. Труды Карельского научного иентра РАН, 5: 35-52 [Lozovik P.A., Borodulina G.S., Karpechko Yu.V., Kondratyev S.A., Litvinenko A.V., Litvinova I.A. Nutrient load on Lake Onego according to field data. Transactions of Karelian Research Centre of RAS [Trudy Karel'skogo nauchnogo centra RAN], 5: 35-52 (in Russian)]

Лозовик П.А., Мусатова М.В. (2013) Методика разделения органического вещества природных вод адсорбцией на диэтиламиноэтилцеллюлозе на автохтонную и аллохтонную составляющие. Вестник МГОУ. Серия «Естественные науки», 3: 63-68 [Lozovik P.A., Musatova M.V. (2013) The method of separation of organic substances of natural waters by adsorption on diethylaminoethylcellulose on autochthonous and allochthonous components. Vestnik MGOU. Series "Natural Sciences" [Vestnik MGOU. Seriya «Estestvennye nauki»], 3: 63-68 (in Russian)]

Лозовик П.А., Рыжаков А.В., Сабылина А.В. (2011) Процессы трансформации, круговорота и образования веществ в природных водах. Труды Карельского научного иентра РАH, 4: 21-28 [Lozovik P.A., Ryzhakov A.V., Sabylina A.V. (2011) Processes of matter transformation, cycles and formation in natural waters. Transactions of Karelian Research Centre of RAS [Trudy Karel'skogo nauchnogo centra RAN], 4: 21-28 (in Russian)]

Озера Карелии. Справочник (2013) Петрозаводск, 464 с. [Lakes of Karelia. Reference book. (2013) Petrozavodsk, 464 p. (in Russian)] 
Рыжаков А.В., Степанова И.А. (2016) Оценка скорости потребления минерального фосфора в природных водах с использованием ингибиторов щелочной фосфатазы. Экологическая химия, 25(3): 172-175 [Ryzhakov A.V., Stepanova I.A. (2016) The rate of consumption of mineral phosphorus in natural waters by using inhibitors of alkaline phosphatase. Environmental Chemistry [Ehkologicheskaya himiya], 25(3): 172-175 (in Russian)]

Современное состояние водных объектов Республики Карелии по результатам мониторинга 1992-1997 г2. (1998) Петрозаводск, 188 с. [Modern state of water objects of the Republic of Karelia on the results of monitoring 1992-1997 (1998) Petrozavodsk, 188 p. (in Russian)]

Состояние водных объектов Республики Карелия по результатам мониторинга 1998 2006 г2. (2007) Петрозаводск, 200 c. [State of water objects of the Republic of Karelia on results of monitoring of 1998-2006 (2007) Petrozavodsk, 200 p. (in Russian)]

Хупер Ф. (1977) Происхождение и судьба органических соединений фосфора в водных системах. Фосфор в окружающей среде. М., Мир, с. 217-231 [Hooper F. (1977) The origin and fate of organic phosphorus compounds in aquatic systems. Phosphorus in the environment. Moscow, Mir, p. 217-231 (in Russian)]

Эмануэль Н.М., Кнорре Д.Г. (1984) Курс химической кинетики. М., Высшая школа, 463 с. [Emanuel N.M., Knorre D.G. (1984) Course of chemical kinetics. Moscow, Vysshaya shkola, 213 p. (in Russian)]

Dillon P.I., Rigler F.N. (1974) A test of a simple nutrients budget model predicting the phosphorus concentration in lake water. Journal of the Fisheries Research Board of Canada, 31(11): 1771-1778

Lozovik P.A. (2013) Geochemical classification surface waters in humid zone based on acid-base equilibrium. Water Resources, 40(6): 631-639

Lozovik P.A., Morozov A.K., Zobkov M.B., Dukhovicheva T.A., Osipova L.A. (2007) Allochtonous and autochthonous organic matter in surface waters in Karelia. Water Resources, 34(2): 204-216

Lozovik P.A., Borodulina G.S. (2009) Nitrogen compounds in the surface and subsurface waters of Karelia. Water Resources, 36(6): 672-682

Ryzhakov A.V. (2013) Kinetic parameters of the transformation nitrogen-containing compounds in natural water. Russian Journal of General Chemistry, 83(13): 2618-2623

Ryzhakov A.V., Kukkonen N.A., Lozovik P.A. (2010) Determination of the rate of ammonification and nitrification in natural water by kinetic method. Water Resources, 37(1): 70-74

Ryzhakov A.V., Sabylina A.V. (2015) Phosphatase activity and phosphorus turnover rate in Lakes Ladoga and Onega. Russian Journal of General Chemistry, 85(13): 2938-2941

Vollenweider R.A. (1975) Input-output models with special reference to the phosphorus loading concept in limnology. Schweizerische Zeitschrift für Hydrologie, 37(1): 53-84 